PALEOCEANOGRAPHY, VOL. 1, NO. 4, PAGES 355-368, DECEMBER 1986

REDUCING POWER OF FERROUS IRON

IN THE ARCHEAN OCEAN, 1 .

CONTRIBUTION OE PHOTOSYNTHETIC

OXYGEN

Louis M. François and

Jean-Claude Gérard

Astrophysical Institute,

University of Liège, Liège, Belgium

Abstract. A quantitative model of the Archean ocean is developed in order to estimate the oxidation rate of dissolved ferrous iron, a key process for the deposition of banded iron formations. The continuity equation including chemical reactions and vertical transport is solved for $O_{2}$ and $\mathrm{Fe} I I$. The oxidation rate ${ }^{2}$ depends on the oceanic pH profile, which is calculated as a function of the atmospheric co pressure. In this first part, the oxidation due to the reaction with photosynthetic oxygen is considered. The results are presented as a function of the oxygen concentration in the mixed layer which was varied between $10^{-10}$ and $10^{-6} \mathrm{~mol} \mathrm{~kg}$. It is shown that this Fe II oxidation by 0 is very efficient and that relatively low 0 , levels are required for the ${ }^{2}$ oxidation rate to be limited by upward transport of iron to the surface ocean. Possible evolutionary paths for the Archean ocean-atmosphere system are discussed by an analysis of the balance of the iron input flux.

\section{Copyright 1986}

by the American Geophysical Union.

Paper number 6P0373.

$0883-8305 / 86 / 006 \mathrm{P}-0373 \$ 10.00$

\section{INTRODUCTION}

During the Archean and early Proterozoic, the earth's history was marked by the deposition of extensive iron-rich sediments. These deposits consist of alternating layers of silica and iron minerals. For that reason, they are commonly refered to as banded iron formations (BIF). It has been proposed that the iron was precipitated from the Precambrian seawater which was assumed to contain several ppm of ferrous iron in solution [Holland, 1973; Drever, 1974]. Since large quantities of ferric iron are present in BIFs, the precipitation requires an oxidizing agent. According to the classical view, this agent would be photosyntetic oxygen. In regions of upwelling, the iron-rich deep water would mix with the surface water containing many oxygen producing organisms. The iron would precipitate in the ferric form, preventing the accumulation of the oxygen in the atmosphere. Therefore according to this view, the existence of extensive BIFs in the sediments would testify to the presence of abundant photosynthetic organisms during the Archean. Another oxidizing agent has, however, been 


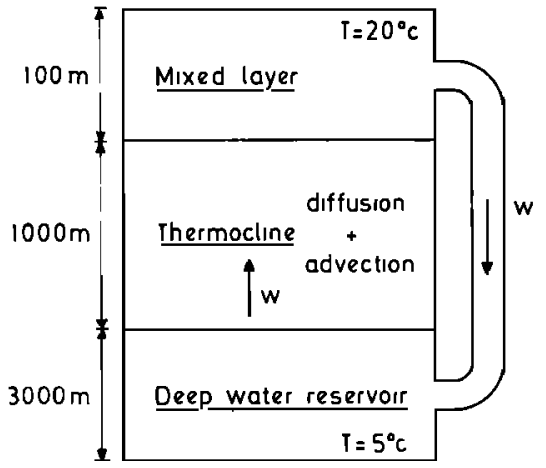

Fig. 1. Vertical structure of the ocean in the model; $w$ is the advective velocity.

proposed by Cairns-Smith [1978] and Braterman et al. [1983]. According to their view, the ultraviolet and visible solar light can photooxidize FeOH ions in the Precambrian seawater. This mechanism takes place at $\mathrm{pH}>6.5$, a range of values which corresponds to the estimated $\mathrm{pH}$ of the Archean ocean [Cloud, 1973; Towe, 1978; Garrels and Perry, 1974]. This photooxidation process does not require the presence of any 1 ife form.

Neither oxidizing process is well known quantitatively. Braterman et al. [1983] first estimated the photooxidation rate through photochemical calculations, for an imposed surface Fe II concentra tion. Recently, François [1986] coupled a similar calculation to a dynamical model of the Archean ocean. The results showed that FeOH photooxidation may have been a very effective oxidizing

mechanism. On the other hand, it is well known that ferrous iron is very unstable in the presence of oxygen. However, no quantitative ocean model involving the kinetics of the reaction has been presented in the past, so that it is not easy to estimate the capacity of the Archean ocean to consume the oxygen released by photosynthesis.

In the present work we propose a quantitative description of $\mathrm{Fe}$ II oxidation in Archean seawater. In view of our poor knowledge of the Precambrian world, this model remains largely speculative. However, since the results are presented for a large range of $\mathrm{Fe} I I$ concentrations in the deep water and of oxygen concentrations in the mixed layer as well as for various atmospheric CO, levels (or equivalently various oceanic $\mathrm{pH}$ ), the model may be applied to many possible states of the Archean ocean. The work is divided into two separate papers. In part 1 the oxidation of Fe II by $Q_{2}$ is modeled in the absence of $\mathrm{FeOH}^{+2}$ photooxidation. The consequences for the evolution of Archean seawater are briefly discussed. In part 2 (L.M. François, manuscript to be submitted, 1986) a calculation of the photooxidation rate will be coupled to the model.

\section{THE MODEL}

The ocean is divided into three regions: the mixed layer, the thermocline and the deep water reservoir (Figure 1). The mixed layer and the deep water reservoir are assumed to be homogeneous and are $100 \mathrm{~m}$ and $3000 \mathrm{~m}$ thick, respectively. The model consists of a chemical calculation coupled to a one-dimensional model of ocean dynamics. The latter solves the continuity equation for 0 and total ferrous iron in the ${ }^{2}$ thermocline, which is assumed to be a diffusive and advective layer with a thickness of $1000 \mathrm{~m}$. The chemical model computes the pH profile in the thermocline.

\section{Calculation of $\mathrm{pH}$}

This calculation describes the concentration of the major oceanic ions in order to derive a $\mathrm{pH}$ profile consistent with an imposed atmospheric $\mathrm{CO}_{2}$ pressure $\left(\mathrm{P}_{\mathrm{CO}_{2}}\right)$. The model is based on the assumption that the Archean oceanic composition is essentially modern. Since the Archean world may have been quite different from the present one, the pH calculation may be thought of as a simple method to reduce the model dependence to only one parameter instead 
TABLE 1. Reactions Considered for the pH Calculation

\begin{tabular}{|c|c|c|}
\hline Reaction & $\log \mathrm{K}$ & Source \\
\hline $\mathrm{K}, \mathrm{Fe}^{2+}+\mathrm{OH}^{-} \stackrel{\mathrm{FeOH}}{+}$ & 3.86 & Davison [1979] \\
\hline $\mathrm{K}_{2} \mathrm{Fe}^{2+}+\mathrm{Cl}^{-} \rightarrow \mathrm{FeCl}^{+}$ & -0.45 & Davison [1979] \\
\hline $\mathrm{K}_{3}^{2} \mathrm{Fe}^{2+}+\mathrm{SO}_{4}^{2-} \rightarrow \mathrm{FeSO}_{4}^{\circ}$ & 0.61 & Davison [1979] \\
\hline $\mathrm{K}_{4}^{2} \mathrm{H}^{+}+\mathrm{SO}_{4}^{2-} \stackrel{\mathrm{HSO}_{4}^{-}}{-}$ & 1.064 & $\begin{array}{l}\text { Dyrssen and Wedborg } \\
\text { [ } 1974]\end{array}$ \\
\hline $\mathrm{K}_{5} \mathrm{HCO}_{3}^{-}+\mathrm{Mg}^{2+} \rightarrow \mathrm{MgHCO}_{3}^{+}$ & 0.017 & $\begin{array}{c}\text { Dyrssen and Wedborg } \\
{[1974]}\end{array}$ \\
\hline $\mathrm{K}_{6} \mathrm{CO}_{3}^{2-}+\mathrm{Mg}^{2+}+\mathrm{MgCO}_{3}^{\circ}$ & 1.512 & $\begin{array}{l}\text { Dyrssen and Wedborg } \\
\text { [1974] }\end{array}$ \\
\hline $\mathrm{K}_{7} \mathrm{HCO}_{3}^{-}+\mathrm{Ca}^{2+}+\mathrm{CaHCO}_{3}^{+}$ & 0.017 & assumed equal to $\mathrm{K}_{5}$ \\
\hline $\mathrm{K}_{8} \mathrm{CO}_{3}^{2 \mathrm{~J}}+\mathrm{Ca}^{2+}+\mathrm{CaCO}_{3}^{\circ}$ & 1.512 & assumed equal to $\mathrm{K}_{6}$ \\
\hline $\mathrm{K}_{9} \mathrm{Mg}^{2+}+\mathrm{OH}^{-}+\mathrm{MgOH}^{+}$ & 1.58 & $\begin{array}{l}\text { Dyrssen and Wedborg } \\
\text { [1974] }\end{array}$ \\
\hline $\mathrm{K}_{10} \mathrm{Ca}^{2+}+\mathrm{OH}^{-}+\mathrm{CaOH}^{+}$ & 0.25 & $\begin{array}{l}\text { Dyrssen and wedborg } \\
\text { [1974] }\end{array}$ \\
\hline $\overrightarrow{+} \mathrm{H}^{+}+\mathrm{OH}^{-}$ & & Millero $[1979]$ \\
\hline$\rightarrow \mathrm{H}^{+}+\mathrm{HCO}_{3}^{-}$ & $\ldots{ }^{*}$ & Gieskes [1974] \\
\hline $\mathrm{K}_{13} \mathrm{HCO}_{3} \stackrel{\leftrightarrow}{\rightarrow} \mathrm{H}^{+}+\mathrm{CO}_{3}^{2-}$ & $\ldots{ }^{*}$ & Gieskes [1974] \\
\hline $\mathrm{K}_{14} \mathrm{H}_{3} \mathrm{BO}_{3} \stackrel{+}{\mathrm{H}^{+}}+\mathrm{H}_{2} \mathrm{BO}_{3}^{-}$ & $\ldots{ }^{*}$ & Gieskes [1974] \\
\hline
\end{tabular}

of a height profile. Consequently, the sensitivity to the $\mathrm{CO}$ pressure which is analyzed below is, in fact, a sensitivity to the $\mathrm{pH}$ profile. Furthermore, a change in the oceanic composition would be formally identical to a $\mathrm{CO}_{2}$ variation, since ultimately either change appears through the $\mathrm{pH}$ profile.

The model ocean contains the following ions in solution: ${ }_{+} \mathrm{Na}^{+}$, $\mathrm{K}^{+}, \mathrm{Mg}^{2+}, \mathrm{Ca}^{2+},-\mathrm{Fe}^{2+}, 2$ and $\mathrm{H}^{+}$for cations and $\mathrm{Ci}^{-} \mathrm{SO}_{4}^{2}, \mathrm{HCO}_{3}^{-} \mathrm{CO}_{3}$, $\mathrm{OH}$, and $\mathrm{H}_{2} \mathrm{BO}_{3}$ for anions. The ions can form ${ }^{3}$ various complexes through the chemical reactions displayed in Table 1. Complexations with $\mathrm{Na}^{+}$and $\mathrm{K}^{+}$have not been included although these two ions contribute to the alkalinity of the water in the model. The equilibrium constants $K_{1}$ to $K, 4$ have been corrected, since in the original parameterization [Millero, 1979;
Gieskes, 1974], they were given in terms of the stoichiometric concentrations of the ions involved in the reaction, i.e., the concentration of the free ion plus the concentrations of its various complexes. In the following text the stoichiometric concentration will be referred to by a subscript $T$. The values of the constants $K$ to $K_{14}$ depend on temperature and salinity. The salinity is set equal to $35 \%$ as in present seawater and the temperature decreases Iinearily from $20^{\circ} \mathrm{C}$ in the mixed layer to $5^{\circ} \mathrm{C}$ in the deep water reservoir.

The stoighiometric concentrations of $\mathrm{Mg}^{2+}$ and $\mathrm{Cl}$ are assumed to be the same as they are today. For sulfate, the value

$$
\begin{aligned}
{\left[\mathrm{SO}_{4}^{2-}\right]_{\mathrm{T}} } & =\left[\mathrm{SO}_{4}^{2-}\right]+\left[\mathrm{HSO}_{4}^{-}\right] \\
& =10^{-}{ }^{\mathrm{mol}} \mathrm{kg}^{-1}
\end{aligned}
$$




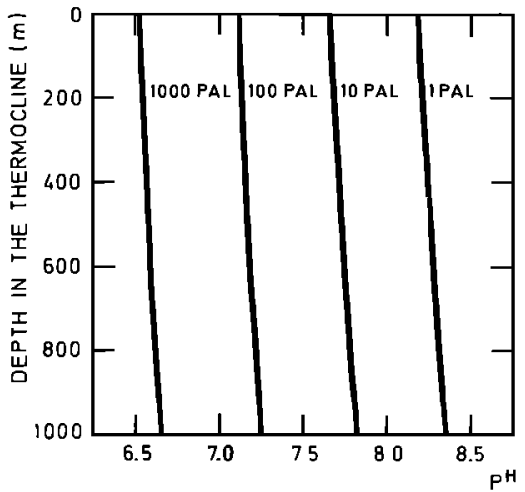

Fig. 2. Profiles of $\mathrm{pH}$ calculated in an iron-free ocean for atmospheric CO, pressures of 1 PAL, 10 PAL, 100 PAE, and 1000 PAL.

has been adopted, based on the discussion of Walker and Brimblecombe [1985]. The calcium concentration is fixed in such a way that the deep water is saturated with respect to calcite. (The parameterization of Miliero [1979] has been used for the solubility product).

The total $\mathrm{CO}_{2}$ concentration $\left(\mathrm{CO}_{2}+\mathrm{H}_{2} \mathrm{CO}_{3}+\mathrm{HCO}_{3}+\mathrm{CO}_{3}^{2}\right)$ is independent ${ }^{3}$ of depth, an assumption made for the sake of simplicity. Indeed, in a real ocean, photosynthesis is a loss of CO from surface water, this Co being restored throughout the water column during the decay of organic matter. These processes are essential in deriving the $\mathrm{pH}$ of present surface water. Furthermore, they control the oxygen profile in the ocean. At low oxygen pressures, however, the rate of decay of organic matter would probably be decreased, so that primary productivity in the mixed layer would be lowered, lessening the influence of $l$ ife on the $\mathrm{CO}$ profile. Since the partial $2_{0}$ pressure in the atmosphere $\mathrm{PCO}_{2}$ is a model parameter, only the $\mathrm{CO}_{2}$ solubility $\mathrm{BCO}_{2}$ is needed to compute the concentration of undissociated $\mathrm{CO}_{2}\left(\mathrm{CO}_{2}+\mathrm{H}_{2} \mathrm{CO}_{3}\right)$ in the mixed layer. $\mathrm{BCO}_{2}=3.24$ The value $10^{-2} \mathrm{~mol} \mathrm{~kg}^{2} \mathrm{~atm}^{-1}$ has been adopted [Weiss. 1974]. Bicarbonate and carbonate concentrations are calculated as a function of $\mathrm{pH}$ by equilibrium relations for reactions (5) to (8), 12 and 13 .

In the model, the sum

$\left[\mathrm{Na}^{+}\right]_{\mathrm{T}}+\left[\mathrm{K}^{+}\right]_{\mathrm{T}}$, assumed to be independent of depth, is chosen in such a way that when $\left[\mathrm{Ca}^{2+}\right]_{\mathrm{T}}$ is equal to its present seawater value and when $\left[\mathrm{Fe}^{24}\right]_{\mathrm{T}}=0$, the alkalinity is equal to the present value of $2.365 \times 10^{-3} \mathrm{eq} \mathrm{kg}$. This figure comes from the results of ocean box models [Broecker, 1981; Knox and McElroy, 1984] and may represent a global average for deep water, in agreement with the measured profiles [Gieskes, 1974; Broecker and Peng, 1982]. At each depth the $\mathrm{pH}$ is calculated from the requirement of electroneutrality. In the thermocline, the calculation has been performed on a $50 \mathrm{~m}$ grid spacing. This pH calcylation needs the concentration $\left[\mathrm{Fe}^{2+}\right]_{\mathrm{T}}$ obtained by the dynamical model as an input. In fact, the $\mathrm{pH}$ is not very sensitive to $\left[\mathrm{Fe}^{2+}\right]_{\mathrm{T}}$, since in our model, even at $1000^{\mathrm{T}} \mathrm{PAL}$ (present atmospheric level) of $\mathrm{CO}_{2}$, an ocean saturated with respect to siperite contains only $-10^{4}$ mol $\mathrm{kg}^{-1}$ of Fe II in the deep water (see Langmuir [1969] for the solubility of siderite), a value which is an order of magnitude lower than the present alkalinity of seawater. On the other hand, the Fe II profile stongly depends on the pH profile. Thus the $\mathrm{pH}$ is calculated first for an ocean devoid of iron and is corrected afterwards as iterations are performed in the dynamical model.

The $p H$ profiles in an iron-free ocean are displayed in Figure 2 , for atmospheric $\mathrm{CO}_{2}$ pressures $\mathrm{PCO}_{\mathrm{CO}}=1,10,100,{ }^{2}$ and $1000 \mathrm{PAL}$. The ${ }^{2} \mathrm{pH}$ in the mixed layer is lower than that in the deep water as a result of a higher temperature and thus higher dissociation constants for $\mathrm{H}_{2} \mathrm{CO}_{3}$ and $\mathrm{HCO}_{3}$. This situation arises in a 1 ifeless ocean, whereas under biological conditions, the $\mathrm{pH}$ might be higher in surface water, as is the case in the present ocean, because of the consumption of surface $\mathrm{CO}_{2}$ by photosynthesis. The influence of $l$ ife on $\mathrm{pH}$ is 


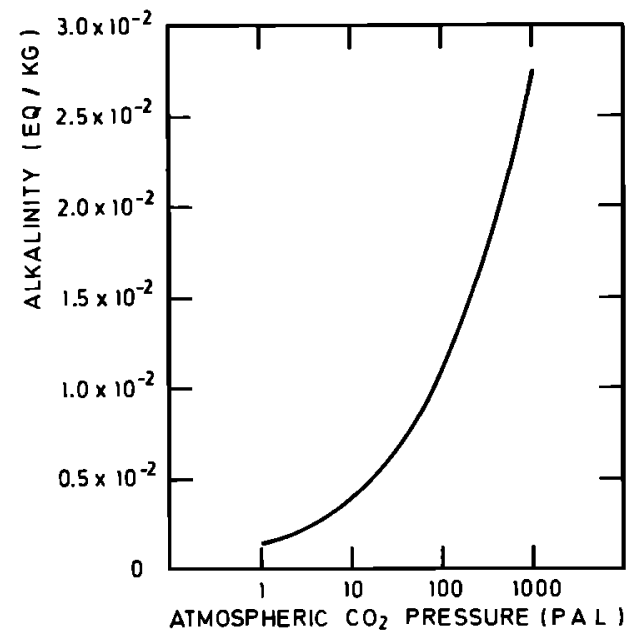

Fis. 3. Alkalinity of an iron-free ocean as a function of the atmospheric $\mathrm{CO}_{2}$ pressure.

probably important only at low $\mathrm{CO}_{2}$ pressures, since at higher $\mathrm{PCO}_{2}$ the relative magnitude of the $\mathrm{CO}_{2}$ blological sink is decreased? This point supports our neglect of the influence of life, since the atmospheric $\mathrm{CO}$ pressure is often presumed to have been higher during the Archean than is today [Holland, 1984; Kasting et al., 1984]. The dependence of the alkalinity on $\mathrm{PCO}_{2}$ is shown in Figure 3. This curve results from the assumption that the ocean remains saturated with respect to calcite when $\mathrm{CO}_{2}$ is varied. At $\mathrm{PCO}_{2}=1 \mathrm{PAL}$, the alkalinity is slightly lower than the present value because of our neglect of the influence of 1 if e.

The kinetics of the reaction between Fe II and oxygen

The kinetics of Fe II oxidation in water containing dissolved oxygen has been studied in laboratory systems by sung and Morgan [1980]. The rate law, which was known much earlier [Stumm and Lee, 1961], has the general form $\frac{d\left[\mathrm{Fe}^{2+}\right] \mathrm{T}}{d t}=-k_{o x}\left[\mathrm{OH}^{-}\right]^{2} \mathrm{P}_{\mathrm{O}_{2}}\left[\mathrm{Fe}^{2+}\right]_{T}$

where $k_{o x}$ is the rate constant and
$\mathrm{PO}_{2}$ is the partial pressure of oxygen in equilibrium with the aqueous solution. The linear dependence with respect to $\mathrm{PO}_{2}$ comes from the assumption that the 2 determining step in the oxygenation process is a firstorder reaction. The calculation of $k$ from experimental data is based on this assumption and has been performed at high $\mathrm{PO}_{2}$. The rate law will nevertheless be adopted here for low PO2values, since no experimental data are available in this range of oxygen concentrations. At a temperature of $25^{\circ} \mathrm{C}$ and with $\mathrm{PO}_{2}=0.2$ atm, Sung and Morgan [1980] found the following dependence of the rate constant upon the ionic strength I

$\log \mathrm{k}_{\circ x}\left(\mathrm{~mol}^{-2} \mathrm{~kg}^{2} \operatorname{atm}^{-1} \mathrm{~min}^{-1}\right)$

$=13.76-2.06 \sqrt{\mathrm{I}}$

This parameterization is not valid at high ionic strengths since it has been deduced in a series of experiments with I ranging from $9 \times 10^{-3}$ to $0.11 \mathrm{M}$. Equation (3) has nevertheless been extrapolated to $I=0.7 \mathrm{M}$, the ionic strength of seawater. This $p \sum^{\circ}$ cedure gives $\mathrm{k}_{\mathrm{ox}}=1.09 \times 10^{12} \mathrm{~mol}^{-2} \mathrm{~kg}^{2} \mathrm{~atm}^{-1}$ ox min $^{-1}$ slightly fess than 1.8 value measured in a solution' 0.50 M NaCl [Sung and Morgan, 1980,

Table IV].

The rate constant $k$ is found to be strongly temperaluredependent. However equation (2) may be written as

$\frac{d\left[\mathrm{Fe}^{2+}\right] \mathrm{T}}{\mathrm{dt}}=-\mathrm{k}_{\mathrm{ox}}^{\prime}\left[\mathrm{OH}^{-}\right]^{2}\left[\mathrm{O}_{2}\right]\left[\mathrm{Fe}^{2+}\right]_{\mathrm{T}}$

$\mathrm{k}_{\mathrm{OX}}^{\prime}=\mathrm{k}_{\mathrm{Ox}} / \mathrm{B}_{\mathrm{O}_{2}}$

where $\mathrm{BO}_{2}$ is the solubility of oxygen and $\left[0_{2}\right]$ is the oxygen concentration in the water. The results of Sung and Morgan [1980] show that k' (unlike k ox ) $25^{\circ} \mathrm{C}, \mathrm{BO}_{2}=10^{-3} \mathrm{~mol} \mathrm{~kg}^{-1} \mathrm{~atm}^{-1}$

[Broecker and Peng, 1982], sq that $k^{\prime}$ i.e. $k^{\prime}=1.09 \times 10^{15} \operatorname{mol}^{-3} \mathrm{~kg}-3 \mathrm{~min} 3$ 
$\mathrm{yr}^{-1}$. This value, adopted in the model, is assumed to be independent of temperature.

The Calculation of Fe II and oxygen Profiles

The oceanic profiles of Fe II and $\mathrm{O}_{2}$ are calculated with a model of global transport. The formation of deep water at high latitudes is modeled by a "pipe" I inking the mixed layer to the deep water reservoir and in which the water circulates downward with a velocity $w=4 \mathrm{~m} \mathrm{yr}$ (Eigure 1). This downward velocity is compensated by an equal upward advective velocity in the thermocline, symbolizing upwelling in the ocean. The continuity equations for Fe II and 0 must be solved in the thermocline where there is no mechanism of production and where the only sink is the oxidation of Fe II by reaction with $0_{2}$. Thus if $z$ is equal to 0 at the top of the thermocline and increases downward, one may write at steady state (in the thermocline, $w$ is chosen positive upward)

$$
\begin{aligned}
& \mathrm{K} \frac{\mathrm{d}^{2}\left[\mathrm{Fe}^{2+}\right]_{\mathrm{T}}}{\mathrm{dz} \mathrm{z}^{2}}+\mathrm{w} \frac{\mathrm{d}\left[\mathrm{Fe}^{2+}\right]_{\mathrm{T}}}{\mathrm{dz}}= \\
& \mathrm{K} \frac{\mathrm{d}^{2}\left[\mathrm{O}_{2}\right]}{\mathrm{dz} \mathrm{z}^{2}}+\mathrm{w} \frac{\mathrm{OH}]^{-}\left[\mathrm{O}_{2}\right]\left[\mathrm{Fe}^{2+}\right]_{\mathrm{T}}}{\mathrm{dz}}= \\
& \frac{1}{4} \mathrm{k}_{\mathrm{Ox}}^{\prime}\left[\mathrm{OH}^{-}\right]^{2}\left[\mathrm{O}_{2}\right]\left[\mathrm{Fe}^{2+}\right]_{\mathrm{T}}
\end{aligned}
$$

where the $1 / 4$ factor accounts for the stoichiometry of the oxidation reaction. The diffusion coefficient $K$ is assumed to be independent of $z$ and equal to $4000 \mathrm{~m}^{2} \mathrm{yr}^{2}$, which is approximately its present value [Oeschger et al., 1975].

To solve this system of equations, four boundary conditions are needed. First, the oxygen concentration in the mixed layer $\left[\mathrm{O}_{2}\right]_{0}$ is a model parameter. If the surface ocean is in equilibrium with the atmospheric oxygen pressure $\mathrm{PO}_{2},\left[\mathrm{O}_{2}\right]_{0}$ is linked to $\mathrm{P}_{2}$ by

$\left[\mathrm{O}_{2}\right]_{0}=\mathrm{B}_{2}\left(20^{\circ} \mathrm{C}\right) \cdot \mathrm{P}_{\mathrm{O}_{2}}$
At high or even moderate 0 pressure, this assumption ${ }_{1}^{2}$ certainly valid. At very low $\mathrm{PO}_{2}$, however, the atmospheric sink of oxygen (reaction with reduced gases) might become important and maintain a disequilibrium between the surface ocean and the atmosphere. Another model parameter is the Fe II concentration in the deep water reservoir. It has been varied between $10^{-9}$ mol $\mathrm{kg}^{-1}$ and the value obtained at siderite saturation (the solubility of siderite is from Langmuir [1969]). Thus the first parameter fixes the oxidation state of the surface ocean linked to the photosynthetic production of oxygen, whereas the second one is a measure of the reducing capacity of the deep ocean, linked to the total input of $\mathrm{Fe}$ II in the ocean. Note that in this study, the maximum iron concentration is 1 imited to the siderite saturation value. In this sense, we follow the work of Holland [1973], who suggested such a saturation. However, the possibility that the Archean ocean may have been oversaturated with respect to siderite cannot be excluded. This point will be discussed in the following section, since it will appear that oversaturation may be treated in a simplifled model. The other two boundary conditions are obtained from the requirement that the mixed layer and the deep water reservoir are at steady state. The input of $\mathrm{Fe} I I$ into the mixed layer from upward diffusion and advection must be balanced by chemical loss through the oxidation reaction and by downward advection in the "pipe". Therefore, since upward advection is exactly balanced by downward advection, it follows that $K\left(\frac{\mathrm{d}\left[\mathrm{Fe}^{2+}\right]}{\mathrm{dz}}\right)_{0}=$

$\mathrm{H}_{\mathrm{s}} \mathrm{k}_{\mathrm{Ox}}\left[\mathrm{OH}^{-}\right]_{0}^{2}\left[\mathrm{O}_{2}\right]_{0}\left[\mathrm{Fe}^{2+}\right]_{\mathrm{T}, \circ}$

where the subscript o refers to values at the top $(z=0)$ of the thermocline and $\mathrm{H}=100 \mathrm{~m}$ is the thickness of the homogeneous mixed layer. 
In a similar way, it is imposed that the input of 0 , to the deep water reservoir is equal to the output, i.e.,

$$
\begin{aligned}
& w\left[\mathrm{O}_{2}\right]_{0}=\mathrm{K}\left(\frac{\mathrm{d}\left[\mathrm{O}_{2}\right]}{\mathrm{dz}}\right)_{D}+\mathrm{w}\left[\mathrm{O}_{2}\right]_{\mathrm{D}} \\
& +\frac{1}{4} \mathrm{H}_{\mathrm{D}} \mathrm{k}_{\mathrm{Ox}}^{\prime}\left[\mathrm{OH}^{-}\right]_{D}^{2}\left[\mathrm{O}_{2}\right]_{\mathrm{D}}\left[\mathrm{Fe}^{2+}\right]_{T, D}
\end{aligned}
$$

The subscript $D$ refers to values at the bottom $(z=1000)$ of the thermocline, and $H_{H}=3000 \mathrm{~m} \mathrm{is}$ the thickness of the nomogeneous deep water reservolr.

We tried to integrate the differential system by a shooting method using a differential equation Gear solver [Gear, 1971]. However, this method was abandoned, since it was revealed to be very unstable, the integration being extremely sensitive to the initially guessed value of $\left(d\left[0_{2}\right] / d t\right)_{0}$. To overcome this difflculty, the differential system has been transformed into a linear system of algebraic equations, written at $\mathrm{N}$ equally spaced gridpoints. Furthermore, since the calculated 0 , profile is very steep, it was necessary to solve the differential system with respect to a new set of variables.

The value $N=1000$ has been adopted. To verify that the mesh size $\Delta z$ obtained with this value of $N$ was not too large, some models were also run with $N=500$. This change had no appreciable effect on the calculated profiles.

The total production of Fe III in moles per square meter per year due to the oxidation of Fe II may be calculated by integrating the chemical loss. For the various reservoirs of the model, these productions are

Mixed layer:

$$
\phi_{S}=p_{W} H_{S} k_{O x}^{\prime}\left[\mathrm{OH}^{-}\right]_{0}^{2}\left[\mathrm{O}_{2}\right]_{0}\left[\mathrm{Fe}^{2+}\right]_{T}, 0
$$

Thermocline :

$\phi_{t h}=\rho_{\mathrm{W}} \int_{0}^{\mathrm{z} D} \mathrm{k}_{\mathrm{Ox}}^{\prime}\left[\mathrm{OH}^{-}\right]^{2}\left[\mathrm{O}_{2}\right]\left[\mathrm{Fe}^{2+}\right]_{\mathrm{T}} \mathrm{dz}$

Deep water :

$\phi_{D}=\rho_{W} H_{D} k_{O X}^{\prime}\left[\mathrm{OH}^{-}\right]_{D}^{2}\left[\mathrm{O}_{2}\right]_{D}\left[\mathrm{Fe}^{2+}\right]_{\mathrm{T}, \mathrm{D}}$ where $z_{p}=1000 \mathrm{~m}$ is the thickness of the thermocline and

$\rho_{w}=1025 \mathrm{~kg} \mathrm{~m}^{-3}$ is the density of seawater. Using (6), we obtain

$$
\begin{aligned}
& K\left\{\left(\frac{\mathrm{d}\left[\mathrm{Fe}^{2+}\right]_{\mathrm{T}}}{\mathrm{dz}}\right)_{D}-\left(\frac{\left.\mathrm{d}] \mathrm{Fe}^{2+}\right]_{\mathrm{T}}}{\mathrm{dz}}\right)_{0}\right\} \\
& +w\left\{\left[\mathrm{Fe}^{2+}\right]_{\mathrm{T}, \mathrm{D}}-\left[\mathrm{Fe}^{2+}\right]_{\mathrm{T}, \mathrm{O}}\right\}=\Phi_{\mathrm{th}} / \rho_{\mathrm{W}}
\end{aligned}
$$

The accuracy at which this equation is verified is a check of the validity of the profiles. In the following calculations it is verified within a maximum error of a few percent.

\section{RESULTS AND DISCUSSION}

The study of Archean paleosols suggests that the atmospheric $\mathrm{CO}_{2}$ pressure may have been equal to ${ }^{2}$ several tenths of PAL at the end of the Archean period [Holland, 1984], while earlier in the earth's history, the low solar luminosity would have required higher $\mathrm{P}_{\mathrm{CO}_{2}}$, from 80 to 600 PAL [Kasting, 1985]. Therefore our model has been run with $\mathrm{PCO}_{2}=10,100$, and $1000 \mathrm{PAL}$. As was mentioned above, the calculation depends on two other parameters: the oxygen concentration in the mixed layer $\left[\mathrm{O}_{2}\right]_{0}$ and the Fe II concentration in ${ }^{2}$ the deep water reservolr $\left[\mathrm{Fe}^{2+}\right]_{\mathrm{T}} \mathrm{D}^{\circ}$ In Figure 4 , the computed oxygen and Fe II profiles are shown $\underline{f} q \mathrm{r} \mathrm{PCO}_{2}=100 \mathrm{PAL}$, $\left[\mathrm{O}_{2}\right]_{0}=10^{-1} \mathrm{~mol} \mathrm{~kg}^{-1}$, with

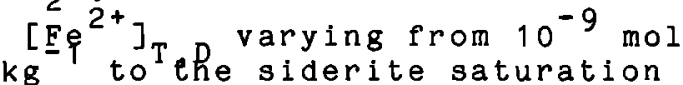
valug, For an ingn-poor deep water $\left(\left[\mathrm{Fe}^{2+}\right]_{\mathrm{T}, \mathrm{D}}=10^{-9} \mathrm{~mol} \mathrm{~kg}^{-1}\right)$, the oxygen concentration is almost constant throughout the thermocline, whereas the surface water is highly depleted with respect to iron. Thus these profiles depict an oxidizing ocean. The oxygen produced in the mixed layer through photosynthesis diffuses downward, and the oxidation of ferrous iron takes place mainly in the deep water. When $\left[\mathrm{Fe}^{2+}\right]_{\mathrm{T}}$ is increased, a sharp $O_{2}$ minimum appears in the thermocine. This minimum is due to the downward advection, symbolizing 


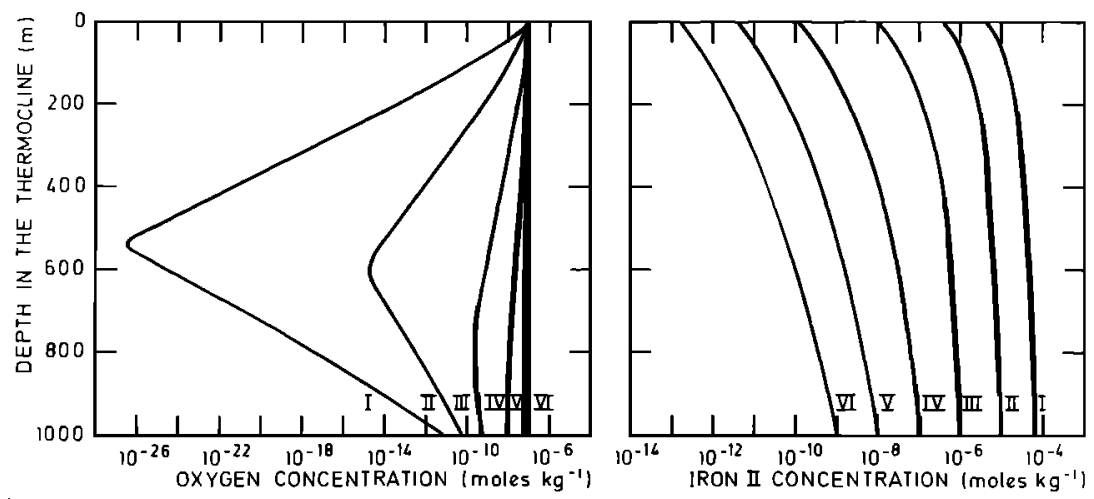

Fig. 4. Oxygen and Fe II profiles obtained for an atmospheric $\mathrm{CO}_{2}$ pressure of $100 \mathrm{PAL}$ and for an $\mathrm{O}_{2}$ concentration of 10 mol $\mathrm{kg}^{-}$in the mixed layer. The $F e$ II concentrations in the deep water are $I,\left[\mathrm{Fe}^{2+}\right]_{\mathrm{T}, \mathrm{D}}=7 \mathrm{x} 10^{-5} \mathrm{~mol} \mathrm{~kg}^{-1}$ (siderite saturation); II, $\left[\mathrm{Fe}^{2+}\right]_{\mathrm{T}}, \mathrm{T}, \mathrm{D}=10^{-5} \mathrm{~mol} \mathrm{~kg}^{-1} ; \mathrm{III},\left[\mathrm{Fe}^{2+}\right]_{\mathrm{T}, \mathrm{D}}=$
$10^{-6} \mathrm{~mol} \mathrm{~kg}^{-1} ; \mathrm{IV},\left[\mathrm{Fe}^{2+}\right]_{\mathrm{T}, \mathrm{D}}=10^{-7} \mathrm{~mol} \mathrm{~kg}^{-1} ; \mathrm{V},\left[\mathrm{Fe}^{2+}\right]_{\mathrm{T}, \mathrm{D}}=$
$10^{-8} \mathrm{~mol} \mathrm{~kg}^{-1} ; \mathrm{VI},\left[\mathrm{Fe}^{2+}\right]_{\mathrm{T}, \mathrm{D}}=10^{-9} \mathrm{~mol} \mathrm{~kg}^{-1}$

deep water formation. The extremely low oxygen concentrations obtained at the minimum show that the oxidation reaction is very effective. As the Fe II concentration is increased, the altitude of the level where the oxidation rate is maximum moves upward so that the production of Fe III in the mixed layer becomes increasingly important. On the other hand, the production of $\mathrm{Fe}$ III in the deep water remains apphoximately constant $\underline{8}_{8}$ once $\left[\mathrm{Fe} \underline{1}_{1}\right]_{\mathrm{T}, \mathrm{D}}$ is greater than $10^{-8}$ mol $\mathrm{kg}^{-1}$. $T$, D Thus for high $\left[\mathrm{Fe}^{2+}\right] \mathrm{T}$, an oxidizing mixed layer 1 les over a reducing deep water.

The total production of Fe III per unit surface is given by

$\phi_{O X}=\phi_{S}+\phi_{t h}+\phi_{D}$

If the ferric iron produced is not reduced to $\mathrm{Fe}$ II in the water column, then $\phi_{0 x}$ may be regarded as the rate of ${ }^{\circ} \mathrm{Fe}$ III deposition in $B I F$ due to the reaction of ferrous iron with photosynthetic oxygen. Furthermore, since four iron atoms are oxidized by only one oxygen molecule, the total sink of 0 per unit surface is equal to $\oint^{2} / 4$. Thus the quantity $\phi$ may help to estimate the capacity of an iron-rich ocean to consume photosynthetic oxygen and to prevent its accumulation in the atmosphere.

In Figure 5 , $\phi_{0 x}$ has been $2+$ plotted as a function of $\left[\mathrm{Fe}^{2+}\right]$ for various oxygen concentrations in the mixed layer. The end of several curves has been suggested by a dashed line. The reason is that for 5 simultaneously high $\left[\mathrm{O}_{2}\right]$ 。 and $\left[\mathrm{Fe}^{2+}\right] \mathrm{T}_{\text {palues, equations }}{ }^{2}$ (6a) and ( $6 B$ ) cannot be integrated on a grid of 1000 points. Indeed, for these models, the differential solver yields negative and unstable values in the upper $300 \mathrm{~m}$ of the thermocline. Consequently, it is not possible to estimate the derivative $\left(\mathrm{d}\left[\mathrm{Fe}^{2+}\right]_{\mathrm{T}} / \mathrm{dz}\right)_{0}$, and equation ( 8 ) cannot $\mathrm{T}^{\mathrm{b}}$ satisfied. If the mesh size is varied, it is observed that the results are altered, indicative of a too large $\Delta z$ value. When the number of grid points is increased by a factor of 3 , the problem is not overcome. A larger increase of $N$ would rapidly become prohibitively time-consuming, since the size of the system of algebraic equations to which (6a) and (6b) are reduced increases in the same ratio. Physically, the problem is linked to the fact that for these oxygen and $\mathrm{Fe} I I$ concentrations, a highly oxidizing mixed layer lies over a 


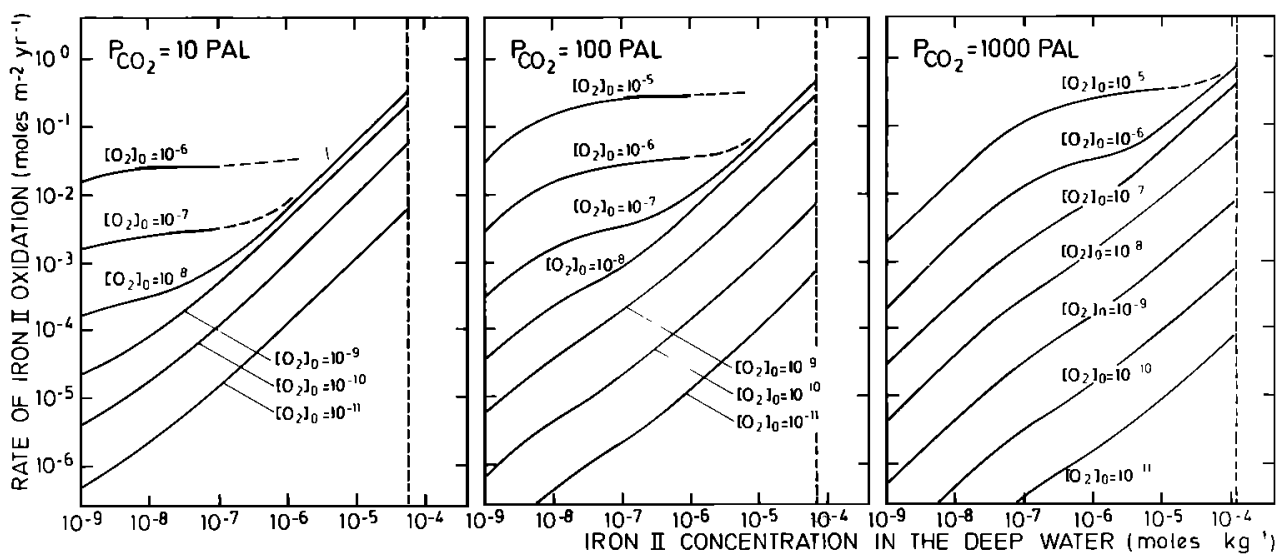

Fig. 5. Rate of Fe II oxidation due to reaction with oxygen as a function of the Fe II concentration in the deep water and of the oxygen concentration in the mixed layer $\left[0_{2}\right]_{0}$.

The vertical dashed 1 ine indicates the Fe II concentration at siderite saturation.

highly reducing deep water so that the $\mathrm{O}_{2}$ and $\mathrm{Fe}$ II gradients must simultaneousiy be very steep in the thermocline. Note that for high $\left[\mathrm{O}_{2}\right]_{0}$ and low $\left[\mathrm{Fe}^{2+}\right] \mathrm{T}, \mathrm{D}$, the problem is more easif ' ${ }^{2}$ solved. since the oxidation rate is smaller, and hence the oxygen concentration in the thermocline may decrease more smoothly. In this case, very small Fe II concentrations were obtained in the mixed layer, so that the Fe II gradient is very steep.

The vertical dashed line in Figyre 5 indicates the value of $\left[\mathrm{Fe}^{2+}\right]_{\mathrm{T}}$ at siderite saturation. This saluration value is not very dependent on the atmospheric $\mathrm{CO}_{2}$ pressure. This weak dependence is due to the fact that at siderite and calcite saturation, when $\mathrm{PCO}_{2}$ is increased, the alkalinity varies in such a way that the decrease in $\left[\mathrm{CO}_{3}^{2-}\right]$ (due to a lower $\mathrm{pH}$ ) is strongly ${ }^{3}$ damped. It must also be pointed out that in the model, an ocean saturated with respect to siderite in the deep water may be supersaturated in the mixed layer, as a result of a greater temperature, except for high surface oxygen concentrations, in which cases the surface iron depletion (see Figure 4) may be large enough to produce undersaturation.
Two simplified models may be useful for very low and very high Fe II concentration in the deep water. As an example, case VI of Figure 4 may be considered. The Fe III production in the various layers of the ocean are

$\Phi_{S}=1.35 \times 10^{-8} \mathrm{~mol} \mathrm{~m}^{-2} \mathrm{yr}^{-1}$

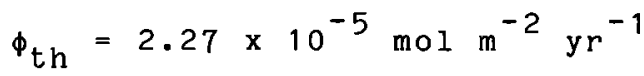

$\phi_{\mathrm{D}}=2.47 \times 10^{-4} \operatorname{mol} \mathrm{m}^{-2} \mathrm{yr}^{-1}$

It is observed that in this case, Fe III is mainly produced in the thick deep water reservoir.

Furthermore, for such low $\left[\mathrm{Fe}^{2+}\right]_{\mathrm{T}}$, the oxygen concentration in the $\mathrm{T}$ deep water is almost the same as that in the mixed layer, provided that the oxygen loss is low enough not to influence the oxygen profile. Consequently, for low $\left[\mathrm{Fe}^{2 \mp}\right]_{\mathrm{T}}$, one may use the following approximation:

$$
\begin{aligned}
\phi_{\mathrm{OX}} & =\phi_{\mathrm{D}}= \\
& \rho_{\mathrm{W}} \mathrm{H}_{\mathrm{D}} \mathrm{k}_{\mathrm{OX}}^{\prime}\left[\mathrm{OH}^{-}\right]_{\mathrm{D}}^{2}\left[\mathrm{O}_{2}\right]_{0}\left[\mathrm{Fe}^{2+}\right]_{\mathrm{T}, \mathrm{D}}
\end{aligned}
$$

Equation (15) means that $\phi_{O x}$ increases linearily with The approximation is better at 
high PCO2, so that the linear behavior is the most obvious for $\mathrm{PCO}_{2}=1000 \mathrm{PAL}$ in Figure 5 . A simple model may also be described for the high concentration limit. In model I of Figure 4, the oxygen concentration in the upper thermocline shows a rapid decrease of several orders of magnitude before reaching a minimum value. In 4 the deep water, $\left[0_{2}\right]$ is always $10^{4}$ times lower than in the mixed layer. On the contrary, the Fe II profile shows only a smooth increase with depth. Consequently, the chemical loss of Fe II is only important in the mixed layer and in the first upper few meters of the thermocline. As a result, it may be assumed that, at high iron concentration, the production of Fe III tends to be restricted to the mixed layer, i.e.,

$$
\begin{aligned}
& \phi_{O X}=\phi_{S}= \\
& \rho_{W} H_{S} k_{o x}^{\prime}\left[\mathrm{OH}^{-}\right]_{0}^{2}\left[\mathrm{O}_{2}\right]_{0}\left[\mathrm{Fe}^{2+}\right]_{\mathrm{T}, 。}
\end{aligned}
$$

The accuracy of this approximation is greater for low $\left[\mathrm{O}_{2}\right]$, since the surface iron depletion is lessened, and for small $\mathrm{PCO}_{2}$, since the more rapid oxidation rate deepens the $\mathrm{O}_{2}$ minimum in the thermocline. In equation (16), the $\mathrm{Fe}$ II

concentration in the mixed layer $\left[\mathrm{Fe}^{2+}\right]$ is not a model parameter. However; ${ }^{\circ}$ it may be simply linked to the concentration in the deep water $\left[\mathrm{Fe}^{2 f}\right]$ if it is noticed that when the ${ }^{\mathrm{T}}$ hemical loss term is neglected (i.e., $\phi_{t h}=0$ ), equation ( $6 a$ ) becomes independent of (6b) and has an analytical solution. If the boundary condition (8) is taken into consideration, the following relationship is obtained:

$$
\begin{aligned}
{\left[\mathrm{Fe}^{2+}\right]_{T, D}=} & {\left[\mathrm{Fe}^{2+}\right]_{\mathrm{T}, 0}+} \\
& \frac{1}{\rho_{\mathrm{W}}} \frac{\phi_{\mathrm{S}}}{\mathrm{w}}\left(1-\mathrm{e}^{-\mathrm{Wz} \mathrm{D}^{/ K}}\right)
\end{aligned}
$$

Combining (16) and (17), we obtain

$$
\phi_{O X}=\phi_{S}=\rho_{W} v_{o x}^{T}\left[\mathrm{Fe}^{2+}\right]_{T, D}
$$

(high $\left[\mathrm{FF}^{2+}\right]_{\mathrm{T}}$ limit), where the velocity $v_{o x}^{T}$ ma be calculated by

$\frac{1}{v_{O X}^{T}}=\frac{1}{v_{o x}^{c h}}+\frac{1}{v_{o x}^{t r}}$

$v_{o x}^{c h}=H_{s} k_{o x}^{\prime}\left[\mathrm{OH}^{-}\right]_{0}^{2}\left[\mathrm{O}_{2}\right] 。$

$v_{o x}^{t r}$

$$
\left.=\frac{w}{\left(1-e^{-W z} D / K\right.}\right)
$$

Physically, $v^{t r}$ is a velocity resulting from adyection and diffusion, and $v$ is a chemifal velocity. The tolal velocity ${ }^{T}$ which governs the response of $\mathrm{CX}_{\mathrm{h}}$ system is a combination of the two velocities, where the lower one is limiting. In Figure 5, the linear dependence of $\phi_{0 x}$ on $\left[\mathrm{Fe}^{2+}\right]$ for the high concentration limit, is clearcut. At low oxygen levels, the production of $\mathrm{Fe}$ IJI is limited by chemistry ( $\left.v_{o x}=v_{\rho x}\right)$, and $\phi_{O x}$ is simply proportional to $\left[\mathrm{O}_{2}\right]_{\circ} \mathrm{ox}$ However, at higher $0_{2}$, the system tepds to the transport-limited $\left(v_{O X}=v_{o x}\right)$, and $\phi_{o x}$ becomes independent of $\left[0_{2}\right]_{0}$. That is the reason why the upper parts of the curves in Figure 4 are equally spaced for low 0 and tend to concentrate when ${ }^{2}\left[\mathrm{O}_{2}\right]_{0}$ increases. The Fe II concentration in the Archean ocean is not known. It is possible that the Archean deep water was oversaturated with respect to siderite. This situation occurs in a range of $\left[\mathrm{Fe}^{2+}\right]$, values for which $(18)$ is valid, except for very high $\left[\mathrm{O}_{2}\right]$ 。. Consequently, in an oversaturated ocean, the Fe II oxidation would take place mainly in the mixed layer, so that the oxygen produced in this layer by photosynthesis would be consumed before it could reach the thermocline or the deep water. The resulting $\mathrm{O}_{2}$ concentrations in these two reservoirs would be so low that their calculation would be of no interest.

The last point which will be discussed is the model sensitivity to the dynamical parameters. Jenkins [1980] suggested that the 
modern upper ocean is ventilated by direct advection from the surface water. If the Archean thermocline was ventilated in this manner, its oxygen content could be appreciably higher than is calculated above. This advective transport cannot be modeled simultaneously with the oceanic circulation in our one-dimensional model. Nevertheless, to estimate the influence of direct ${ }_{2}$ transport from the mixed layer to the thermocline, the value of the diffusion coefficient $K_{2}$ has increased to $K=8000 \mathrm{~m}^{2} \mathrm{yr}^{-1}$ for case I of Figure 4. Since in this case the $0_{2}$ gradient is very steep, the profile must be very sensitive to the increase of $K$. The calculation shows that the $\mathrm{O}_{2}$ minimum is much less pronounced, ${ }^{2}$ the peak concentration being equal to $-10^{-21} \mathrm{~mol} \mathrm{~kg}^{-1}$ instead of $-3 \times 10-27$ mol $\mathrm{kg}^{-1}$. The $\mathrm{O}_{2}$ concentration is increased throughout the thermocline, but the deep water value $\left[\mathrm{O}_{2}\right]_{\mathrm{D}}$ is almost the same ( $\left[\mathrm{O}_{2}\right]_{\mathrm{D}}$ is governed mainly by the oceanic circulation, i.e., by $w)$. The changes in the Fe II profile are minor, except in the mixed layer, where the concentration is increased by a factor of 1.5 , resulting in a similar increase in $\phi_{0 x}$, since at high $\left[\mathrm{Fe}^{2+}\right]_{\mathrm{T}, \mathrm{D}}, \phi_{\mathrm{S}}$ is $\mathrm{the}$ principal contribution, $f_{0}$ the oxidation flux. Case III of Figure 4 has also been rerun with $\mathrm{K}=8000 \mathrm{~m}^{2} \mathrm{yr}^{-}$. For this model, the oxidation takes place mainly in the thermocline. The $\left[\mathrm{O}_{2}\right]$ increase in this layer due to higher diffusion rates may thus change appreciably the oxidation flux. Indeed, $\phi_{o x}$ increases by a factor of 1.6 .

IMPLICATIONS FOR THE ARCHEAN EVOLUTION OF THE ATMOSPHERE AND OCEANS

In order to estimate the consequences of the model on the Archean evolution of the oceanatmosphere system, it is of interest to discuss the balance between the geochemical fluxes of oceanic iron. In the present model it is assumed that no reduction of Fe III takes place in the mixed layer or in the thermocline. Such a reduction may possibly be taken into account for the deep water. Let $\phi_{\text {red }}$ denotes the rate of this Fe IIIedreduction. Under this assumption, the deposition rate of Fe III in BIFs is

$\phi_{B I F}=\phi_{O X}-\phi_{\text {red, D }}$

Consequently, the quantity $\phi_{\circ}$, maximum value of $\phi_{B I F}$. However, it may be argued that ${ }^{B I F}$ in view of the low solubility of ferric coumpounds, the residence time of Fe III in the water column would be low, and thus reactions with high kinetics constants are needed for the reduction to be effective. A reduction in the sediment followed by upward diffusion of Fe II to the overlying water is also possible. A quantitative assessment of this process would require a model of diffusion and chemistry in the sedimentary layer. However, the upward diffusion would only be effective at low $\left[\mathrm{Fe}^{2+}\right]_{\mathrm{T}, \mathrm{D}}$, and as will be seen, we arg mainly interested in the high $\mathrm{Fe}^{2+} 1 \mathrm{imit}$. Thus we may assume that $\phi_{0 x}$ represents a good estimate of $\phi$ BIF.

The geochemical balance of oceanic iron is given by

$\phi_{\text {in }}=\phi_{\text {BIF }}+\phi_{\text {sed }}$

In this equation, $\phi_{j n}$ is the total input flux of iron to the ocean, and $\phi_{\text {sed }}$ is the sedimentary sink of ferrousdiron (deposition of siderite, ferrous silicates, pyrite, etc.).

Before the appearance of green plant photosynthesis, the only source of oxygen was the photodissociation of water vapor in the atmosphere, followed by escape of hydrogen to space. According to Kasting et al. [1984], the ground level mixing ratio of atmospheric oxygen would have been lower than 10-11 PAL. It is clear, from the present model, that the rate of 


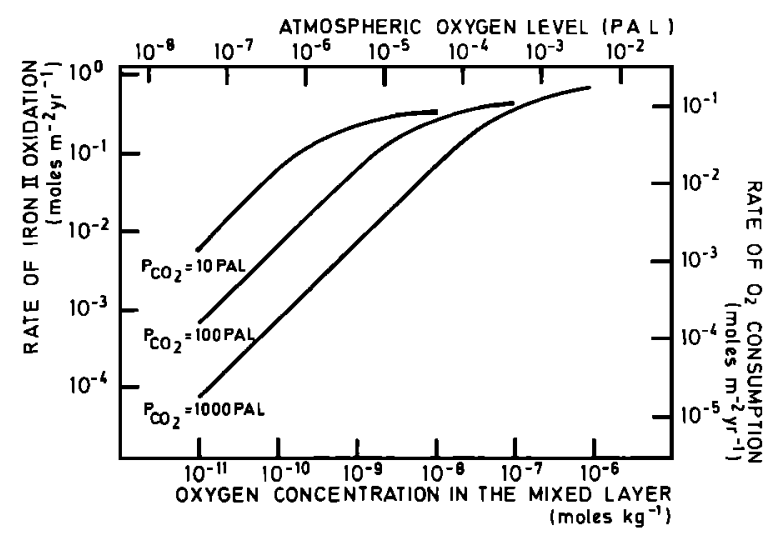

Fig. 6. Rate of Fe II oxidation due to reaction with oxygen as a function of the oxygen concentration in the mixed layer, for an ocean with deep water at siderite saturation. The equilibrium atmospheric oxygen level is represented on the upper scale, and the rate of 0 consumption is shown on the right-hand scale.

Fe II oxidation induced by such a low 02 mixing ratio is extremely small. We propose to draw some interesting conclusions about the evolution of the system due to a progressive increase of the oxygen concentration after the development of green plants.

In what follows, the possible evolutionary path which is presented is based on the assumption that when $\phi_{\text {B }}$ is too low to balance $\phi_{i n}$, the is saturated with respect to siderite. However, from a qualitative point of view, if the deep ocean was oversaturated with respect to siderite, the main features of the evolution would be similar. Moreover, in such a case, the magnitude of the oxidation rate $\phi_{\text {ox }}$ can still be predicted from equation (18). Thus initially, the rate of $\mathrm{Fe}$ II oxidation is close to zero, and the deep water is saturated with respect to siderite. As the photosynthetic oxygen source is increased, the representative point of the ocean moves upward along the vertical dashed line of Figure 5, and the rate of Fe II oxidation $\phi$ increases proportionalyy to $\left[\mathrm{O}_{2}\right]_{0}$, according to equation (18) (with vtr $\gg v_{\text {ox }}^{\text {ch). }}$ During this increase, thex 0 and Fe II profiles are similar to those of case I in Figure 5, i.e., a midly oxidizing mixed layer overlie a highly reducing thermocline and deep water. If the total input flux $\phi_{\text {in }}$ is not too high, the linear increase of $\phi$ will continue until it reaches ${ }^{a}$ magnitude similar to that of $\phi_{i n}$, at which time the ocean will become undersaturated with respect to siderite, and oxygen w111 progressively invade the thermocline and the mixed layer. In other words, when $\phi$ becomes equal to $\phi_{i n}$, the representative point of the model leaves the saturation vertical line of Figure 5 to move approximately along a horizontal line. If the total input flux is higher, the increase of $\phi$ during the saturation phase will proceed further and the oxidation rate will tend to be limited by transport, since the velocity $v$ increases with $\left[\mathrm{O}_{2}\right]_{0}$. As a result, the increase of $\phi$ will be slower, and according $x_{0}$ equation (18), its value will tend to be close to -0.6. (This value, obtained at siderite saturation, increases linearily with $\left[\mathrm{Fe}^{2+}\right] \mathrm{T}$ in the case of oversaturation:? In these conditions, a highly reducing deep water would be overlaid with a highly oxidizing mixed layer. From Figure 5, it may be seen that the surface oxygen $\underline{-}_{8}$ concentration would vary from $-10^{-8}$ to $-10^{-6}$ mol $\mathrm{kg}$ for $\mathrm{PCO}_{2}$ varying from $10 \mathrm{PAL}$ to 1000 PAL. In reality, the 0.6 limiting value for $\phi$ is not strict. Indeed, if $\left[8_{2}\right]_{0}$ were further increased, the oxygen would penetrate deeper in the

thermocline, and the assumption that the principal contribution to $\phi$ comes from the oxidation in the mixed layer would no more be justified, so that equation (15) would no longer be valid.

Unfortunately, the complete model cannot be integrated to describe this situation, since as was mentioned earlier, the oxygen and Fe II profiles in the thermocline must simultaneously be very steep. 
It is possible that these numerical difficulties are linked to an instability of the physical solution, but this is far from being certain. In Figure 6 the oxidation flux $\phi$ for the siderite saturation case has been plotted as a function of the oxygen concentration in the mixed layer. The linear increase at low $\left[\mathrm{O}_{2}\right]_{0}$ as well as the limiting influence of dynamics at high $\left[0_{2}\right]$ o are obvious. The oxidation flux $\Phi_{0}$ constitutes a sink for oxygen. The rate of oxygen consumption which is equal to $\phi_{0 x} / 4$ is given on the right-hand scalex of Figure 6 . On the top scale we have indicated the atmospheric oxygen level calculated from $\left[\mathrm{O}_{2}\right]_{0}$ by the equilibrium equation (7)? These curves may be used to estimate the oxygen demand of an ocean saturated with respect to siderite. Consequently, they are useful to study the evolution of atmospheric oxygen as a function of the photosynthetic source.

\section{CONCLUSIONS}

In this paper a quantitative model describing the oxidation of Fe II in the Archean ocean has been presented. The oxidation by reaction with photosynthetic oxygen has been studied quantitatively. It was shown that the rate of Fe II oxidation is proportional to the oxygen concentration in the mixed layer, except at high oxygen levels, in which cases the oxidation rate is limited by transport of $\mathrm{Fe}$ II from the deep water reservoir to the photosynthetic surface layer. Very steep $0_{2}$ gradients are possible at high oxygen levels, a highly oxidizing mixed layer overlying a reducing deep water.

The exact evolutionary path of the ocean-atmosphere system cannot be determined from the present model, since it depends on the Fe II geochemical fluxes into and out of the ocean. Instead, this model may be used to estimate the reducing capacity of the ocean under preimposed geochemical conditions. A similar study will be presented in part 2(L.M.
François, manuscript to be submitted, 1986) to describe $\mathrm{FeOH}^{+}$ photooxidation and its effects in the presence of $\mathrm{O}_{2}$.

Acknowledgments. One of us (J.C.G) is supported by the Belgian National Foundation for scientific Research. We thank $R$. Scuflaire for helpful suggestions concerning the numerical method.

\section{REFERENCES}

Braterman, P. S., A. G. CairnsSmith and R. W. Sloper, Photooxidation of hydrated Fe $\mathrm{Fe}^{+-}$-Significance for banded iron formations, Nature, 303, 163-164, 1983.

Broecker, W. S., Glacial to interglacial changes in ocean and atmosphere chemistry, in Climatic Variations and Variability : Facts and Theories, edited by A. Berger, pp.111-121, D. Reidel, Hingham, Mass., 1981.

Broecker, W. S., and T. H. Peng, Tracers in the sea, LamontDoherty Geological observatory, Palisades, New York, 1982.

Cairns-Smith, A. G., Precambrian solution photochemistry, inverse segregation, and banded iron formations, Nature, 276, 807-808, 1978 .

Cloud, P., Paleoecological significance of the banded ironformation, Econ. Geol., 68, 11351143,1973 .

Davison, W., Soluble inorganic ferrous complexes in natural waters, Geochim. Cosmochim. Acta, 43, 1693-1696, 1979 .

Drever, J. I., Geochemical model for the origin of Precambrian banded iron-formations, Geol. Soc. Am. Bull., 85, $1099 \overline{-1106}$, 1974 .

Dyrssen, D., and M. Wedborg, Equilibrium calculations of the speciation of elements in seawater, The sea, vol.5, edited by E.D. Goldberg, pp.181-195, Interscience, New York, 1974.

François, L. M., Extensive deposition of banded ion formations was possible without photosynthesis, Nature, 320, 352-354, 1986 . 
Garrels, R. M., and E. A. Perry, Cycling of carbon, sulfur and oxygen through geologic time, in The Sea, vol.5, edited by E.D. Goldberg, pp.303-326, Interscience, New-York, 1974.

Gear, C. W., Numerical Initial Value Problems in ordinary Differential Equations, PrenticeHall, Englewood Cliffs, N.J., 1971 .

Gieskes, J. M., The alkalinitytotal carbon dioxide system in seawater, in The Sea, vol.5, edited E.D. Goldberg, pp.123-151, Interscience, New-York, 1974.

Holland, H. D., The oceans: A possible source of iron in ironformations, Econ. Geol., 68, $1169-1172,1973$.

Holland, H. D., The Chemical Evolution of the Atmosphere and oceans, Princeton University Press, Princeton, N.J., 1984. Jenkins, W. J., Tritium and ${ }^{3} \mathrm{He}$ in the Sargasso Sea, J.Mar. Res., $38,533-569,1980$.

Kasting, J.F., Photochemical consequences of enhanced $\mathrm{CO}_{2}$ levels in earth's early atmosphere, in The carbon cycle and atmospheric CO: Natural Variations Archean 2 to Present, Geophys. Monogr. Ser., vol. 32 , edited by E. T. Sundquist and $W$. S. Broecker, pp. 612-622, AGU, Washington, D.C., 1985 .

Kasting, J.F., and J. B. Pollack, and $D$. Crisp, Effects of high $\mathrm{CO}_{2}$ levels on surface temperature and atmospheric oxidation state of the early earth, J.Atmos. Chem.' $1,403-428,1984$.

Knox, F., and M. B. Mc Elroy, Changes in atmospheric $\mathrm{CO}_{2}$ : Influence of the marine blota at high latitude, J. Geophys. Res., 89, 4629-4637, 1984.
Langmuir, D., The Gibbs free energies of substances in the system $\mathrm{Fe}-\mathrm{O}_{2}-\mathrm{H}_{2} \mathrm{O}-\mathrm{CO}_{2}$ at $25^{\circ} \mathrm{C}$., U.S. Geol. Surv. Prof. Pap. $650-\mathrm{B}$ 180-184, 1969 .

Millero, F. J.. The thermodynamics of the carbonate system in seawater, Geochim. Cosmochim. Acta, 43, 1651-1661, 1979.

oeschger, H., U. Siegenthaler, U. Schotterer, and A. Gugelmann, A box diffusion model to study the carbon dioxide exchange in nature, Tellus, 27 168-192, 1975.

Stumm, W., and G. F. Lee, Oxygenation of ferrous iron. Ind. Eng. Chem, 53, 143-146, $196 \overline{1 .}$

Sung, W.., and J. J. Morgan, Kinetics and product of ferrous iron oxygenation in aqueous systems, Environ. Sci. Technol..'

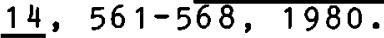

Towe, K. M., Early Precambrian oxygen: A case against photosynthesis, Nature, 274, 657-661, 1978 .

Walker, J.C. G., and P. Brimblecombe, Iron and sulfur in the pre-biologic ocean, Precambrian Res., 28, 205-222, 1985 .

Weiss, R. F., Carbon dioxide in water and seawater: The solubility of a non-ideal gas, Mar. Chem., 2, 203-215, 1974.

L. M. François and J.-C. Gérard, Astrophysical Institue, University of Liège, Avenue de Cointe, 5 , B-4200 Cointe-Liège, Belgium.

(Received February 21, 1986 ; revised June 17, 1986; accepted July $7,1986$. ) 